\title{
Materialismo histórico-dialético: contributos para a investigação em educação
}

\section{Historical-dialectical materialism: contributions to qualitative research in education}

\author{
Lígia Márcia Martins* \\ Tiago Nicola Lavoura**
}

\begin{abstract}
RESUMO
O presente trabalho apresenta contributos do método denominado de materialismo histórico-dialético para as investigações em educação. Ao tempo em que se espera lançar argumentos que possam servir de fundamentos e de parâmetros de análises para as investigações em educação, norteadas pela premissa científica da busca pela inteligibilidade da realidade social, colocaremos em destaque as seguintes questões teórico-metodológicas: a relação entre a dimensão ontológica e a dimensão epistemológica da realidade, e os fundamentos teóricos que sustentam as categorias de análise do objeto investigado. Na sequência, procederemos à transposição dos referidos preceitos para as pesquisas denominadas empíricas e teórico-conceituais.
\end{abstract}

Palavras-chave: Materialismo histórico-dialético. Método. Conhecimento científico.

\footnotetext{
ABSTRACT

The present text intends to present contributions of the method named historical-dialectic materialism to the qualitative investigations in education. We expect to launch arguments that can serve as foundations and parameters of analysis for research in education, as guided by the scientific premise of the search for the intelligibility of social reality. We will highlight the

* Universidade Estadual Paulista. Programa de Pós-Graduação em Educação Escolar. Araraquara, São Paulo, Brasil. E-mail: ligiamar@fc.unesp.br. https://orcid.org/0000-0002-4293-9580.

** Universidade Estadual de Santa Cruz. Ilhéus, Bahia, Brasil. E-mail: nicolalavoura@ gmail.com. https://orcid.org/0000-0003-4382-0415.
} 
following theoretical and methodological issues: the relationship between the ontological dimension and the epistemological dimension of reality, as well as the theoretical foundations that support the categories of analysis of the investigated object. Then, we will transpose these precepts into the so-called empirical and theoretical-conceptual researches.

Keywords: Historical-dialectical materialism. Method. Scientific knowledge.

\section{Introdução}

O objetivo do presente trabalho é realizar uma reflexão acerca da investigação em educação, sobretudo no que se refere à temática dos fundamentos metodológicos da pesquisa nesta área. Para tanto, busca-se apresentar algumas contribuições do método de investigação denominado de materialismo histórico-dialético, método de conhecimento da realidade concreta sistematizado por K. Marx e F. Engels, cujas bases e elementos centrais são resultantes de um longo e rigoroso processo de investigação, encontrando-se sintetizados no famoso texto de Marx (2011), intitulado A introdução de 1857 - O método da economia política.

Enquanto os fundamentos do método estão sendo apresentados, intenta-se relacioná-los com questões centrais que se entendem fulcrais para toda e qualquer investigação científica, com destaque aqui para as pesquisas em ciências humanas e sociais e, especialmente, na educação, quais sejam: a relação entre a dimensão ontológica e a dimensão epistemológica da realidade, bem como, o tratamento dado às categorias de análise do objeto investigado. Igualmente, visa-se lançar luz à transposição dos referidos preceitos para as pesquisas denominadas empíricas e conceituais ou teóricas.

Com isso, espera-se fornecer argumentos que possam servir de fundamentos e parâmetros de análise para as investigações em educação norteadas pela premissa científica da busca pela inteligibilidade da realidade concreta.

\section{O método em questão: relação entre a dimensão ontológica e a dimensão epistemológica da realidade}

As investigações científicas, as quais possuem como estofo metodológico de análise o materialismo histórico-dialético, possuem como premissa 
central a necessidade de compreender e de explicar os objetos e fenômenos investigados, tais quais eles verdadeiramente são na prática. Diante disso, há um pressuposto de análise em questão que não se pode deixar de explicitar: a dimensão epistemológica do conhecimento científico que permite a humanidade a sistematizar um conjunto de postulados acerca de como é possível conhecer a realidade natural e social. Nesta está subsumida à dimensão ontológica dessa mesma realidade, aquela que permite explicitar o que ela é verdadeiramente, constituindo-se histórica e socialmente por meio da própria atividade prática realizada pelo conjunto dos homens (NETTO, 2011).

Tal premissa carrega consigo duas importantes características, como assinalado por autores como Marx e Engels (2007), Lukács (1967) e Pinto (1979): a primeira, a de que os objetos e fenômenos do real possuem uma existência objetiva, ou seja, a consideração e o reconhecimento da objetividade da realidade. Independentemente do conhecimento e da consciência humana sobre tal, os elementos constitutivos da prática social existem, são reais e possuem uma estrutura e dinâmica interna de funcionamento efetivo a qual pode ser apreendida pela consciência humana por meio, especialmente, da atividade de investigação científica. Decorre daí a necessidade da ciência na prática humana.

Disso se desdobra a segunda característica do método em questão diante do postulado da dimensão ontológica como efetivamente anterior à dimensão epistemológica: a de que os objetos e fenômenos da realidade concreta podem ser apreendidos gnosiologicamente pelos homens. Ou seja, é possível compreender e explicar o que as coisas verdadeiramente são em sua existência efetiva.

Dentre as diferentes formas ou modalidades de conhecimento do real produzidas historicamente pela humanidade, estamos aqui a discutir o conhecimento científico, uma modalidade muito peculiar de conhecimento e explicação da vida humana. À luz do materialismo histórico-dialético, o conhecimento científico se constitui na prática social humana à medida que a própria vida social vai se desenvolvendo e se complexificando, e os homens vão adquirindo condições determinadas social e culturalmente de refletir e teorizar (com métodos cada vez mais desenvolvidos) sobre essa mesma prática social e seus objetos e fenômenos constitutivos. Trata-se, por conseguinte, de se conceber o conhecimento como produto do trabalho dos indivíduos que são historicamente situados, de decodificação abstrata sobre a realidade concreta.

Tal condição assinala outro postulado que aqui há de ser considerado e que pode ter toda a relevância para as investigações em educação: a atividade científica é uma atividade essencialmente teórica, ou seja, é a reprodução ideal (da ordem do pensamento) dos objetos e fenômenos da realidade em seu movimento real (MARX; ENGELS, 2007). 
Reproduzir no plano do pensamento o movimento real do objeto ou fenômeno é o que se entende por teoria, sinônimo de conhecimento científico para o método em questão. O conhecimento teórico é o conhecimento do objeto, o conhecimento do seu movimento real reproduzido em pensamento (NETTO, 2011), reafirmando-se o postulado da concepção ontológica de teoria. Reprodução aqui assume o significado de reconstrução, no plano do pensamento, daquilo que se passa anteriormente na realidade efetiva.

Todavia, tal reprodução do objeto em pensamento não deve ser compreendida como um espelhamento, como uma imagem fotográfica, mas, sim, como processualidade histórica e dinâmica, características cuja realidade necessariamente é portadora. Portanto, a investigação sobre o social deve levar em conta o constante movimento dos objetos e dos fenômenos em seu devir, o que significa levar em consideração a herança hegeliana de que ser é vir-a-ser.

A apreensão teórica pelo investigador do movimento real, prático e efetivo do objeto ou fenômeno investigado, por sua vez, não pode ser realizada de forma imediata. O processo de conhecimento para o materialismo histórico-dialético não se dá por intermédio do imediatismo do pensamento. O conhecimento do real não pode se limitar àquilo que é imediatamente dado, pensado ou sentido. Se o pensamento se limita a isso, ele se põe no nível da obviedade, restringe-se a captar o evidente. Além disso, há que se considerar a efetiva distinção entre a aparência e a essência dos processos do real, como assinalou Marx (2008), ao afirmar que se a aparência das coisas se confundisse com sua essência, toda ciência seria supérflua. Dessa maneira é que se pressupõe um caminho de investigação de superação do nível empírico ao nível concreto do real, superação essa que só é possível - para esse método de pesquisa - por meio da análise e da abstração do pensamento do investigador.

A aparência fenomênica, imediata e empírica da realidade é importante e não pode ser descartada, visto que ela é o ponto de partida do processo do conhecimento - portanto, necessariamente onde se inicia o conhecimento. Entretanto, deve-se, partindo da aparência, alcançar a essência do objeto de estudo, capturar sua lógica interna de funcionamento que corresponde à estrutura e à dinâmica essencial. Com efeito, Marx (2011) não deixa dúvidas quanto à capacidade intelectiva da abstração como aquela necessária para se realizar o procedimento analítico de ultrapassagem da aparência imediata da realidade. É ela - a abstração - que permite extrair um elemento da realidade, isolá-lo e examiná-lo nas suas particularidades, extraindo deste elemento suas múltiplas determinações por meio da saturação da análise. Apreender um fenômeno como síntese de múltiplas determinações significa, em última instância, apreendê-lo no complexo de relações que comportam sua existência objetiva. 
A abstração é um recurso decisivo do pensamento para se alcançar aquilo que Marx (2011) denominou de as determinações mais simples do objeto, determinações estas altamente complexas e que se caracterizam pelos traços constitutivos pertinentes ao objeto. As determinações do objeto carregam os traços essenciais da dinâmica e da estrutura do funcionamento do objeto investigado, permitindo explicitar a lógica de sua existência efetiva. Com efeito, elas podem ser alcançadas por meio de um recurso analítico-formal.

Entretanto, embora a lógica formal tenha uma função específica e importante no processo de conhecimento da realidade, visto que busca identificar, caracterizar e classificar os elementos por si mesmos e em suas especificidades, ela se mostra insuficiente para apreender a realidade em sua dinamicidade, processualidade e em movimento (OLIVEIRA, 2005).

Apesar de que a lógica formal seja necessária para identificar cada elemento da realidade em suas características específicas e classificá-los conforme parâmetros e princípios inerentes do processo de conhecimento, ela não possibilita captar as relações e as mediações dos múltiplos elementos do real. Seu critério lógico de identificação, organização, catalogação e classificação de cada complexo constitutivo da realidade é uma organização meramente lógico-formal dos elementos do real, elementos estes considerados estáticos, sem movimento. É por isso que Marx (2011) irá afirmar que o verdadeiro caminho do conhecimento científico é o que se dá por meio da ascensão do abstrato em direção ao concreto.

Ascender do abstrato ao concreto significa, para o materialismo histórico-dialético, captar o conjunto dos nexos e relações dos diferentes elementos que constituem a totalidade de um objeto ou fenômeno. Vale dizer, apreender as relações entre as diferentes determinações mais simples as quais se constituem como unidade mínima de análise e que possibilitam explicar a coisa investigada na sua totalidade, num movimento lógico dialético que vai do todo às partes e das partes ao todo constantemente ${ }^{1}$.

Apreender as relações dinâmicas e processuais do conjunto das determinações de um objeto ou fenômeno e sintetizá-las teoricamente é o significado do conhecimento científico para o método de conhecimento da realidade. Tal como afirmou Marx (2011), o verdadeiro conhecimento é a síntese de múltiplas determinações e relações numerosas, ou seja, uma rica totalidade de determina-

1 A categoria de totalidade é entendida na perspectiva do materialismo histórico-dialético como uma unidade de máxima complexidade constituída por diferentes elementos também complexos (com menores graus de complexidade), os quais, em suas relações, constituem e sintetizam aquela totalidade. Conforme afirmou Lukács (2013), a totalidade é um complexo constituído de complexos, uma vez que cada parte ou elemento constitutivo da totalidade é por ela determinado, bem como, também a determina. Conhecer a totalidade de um objeto ou fenômeno não significa conhecer tudo, mas, sim, apreender a lógica determinante dessa totalidade. 
ções em suas relações constitutivas, de modo que se considera como importantes tarefas das ciências estudar e explicar de um modo historicamente concreto um objeto ou fenômeno singular, analisado em suas condições estruturais mais gerais e universais (o que requer uma análise lógico-sincrônica) e as suas transformações históricas particulares, desde sua gênese até seu desenvolvimento efetivo (o que requer uma análise histórico-diacrônica do objeto). Essa é a síntese do método lógico-histórico em discussão, a ser ampliada no tópico subsequente.

\section{Princípios gerais da dialética materialista e suas relações com as categorias de análise do objeto investigado}

Como afirmado anteriormente, para o materialismo histórico-dialético há que se ter uma separação clara entre o que é da ordem da realidade, portanto, aquilo que de fato é propriedade do objeto ou fenômeno investigado, daquilo que é da ordem do pensamento, ou seja, aquilo que se constitui como o conhecimento operado pelo sujeito investigador. Como bem destaca Marx (2011), o grande equívoco de Hegel e de toda a filosofia idealista foi o de confundir o que é da ordem do pensamento com aquilo que é da ordem do real, sucumbindo ao erro de que o pensamento é, em última instância, criador da própria realidade.

Há que se ter sempre em vista que em todos os processos investigativos da realidade social as categorias de análises expressam formas de ser do objeto ou fenômeno investigado, sendo, portanto, formas de existência, ontológicas e históricas, do objeto em questão. Para o método de investigação em questão, analisar e investigar um objeto ou fenômeno é ir à busca dos traços essenciais que o mesmo é portador, operando o sujeito investigador com graus cada vez maiores de abstração que permitam chegar a unidades de análise cada vez mais tênues e simples, encontrando no objeto investigado aquilo que no conjunto o determinam, as determinações do objeto. O objeto investigado é portador dessas determinações, mas o pensamento é que as reproduz idealmente por meio das categorias teóricas. Quanto mais se satura um objeto de determinações mais se concretiza. Concreção que é da ordem da realidade, e não do pensamento.

Ocorre que esse conjunto de determinações do objeto não se revela na imediatez factual do mesmo. É preciso extrair do objeto as suas determinações, pois são constitutivas dele e somente podem ser alcançadas e reproduzidas em pensamento por meio do processo de abstração analítica do investigador, que tem como instrumentos para tanto as categorias de análise e os conceitos nelas consubstanciados. As categorias, portanto, são elaborações lógicas do sujeito 
pensante, configurando-se como expressão lógica da realidade concreta, por isso são categorias ontológicas.

Como se vê, a investigação científica é um verdadeiro processo de enriquecimento do pensamento do sujeito investigador, que se confronta com o objeto investigado em um processo de sucessivas aproximações, visto que as determinações não estão isoladas entre si. Elas estão articuladas dentro da totalidade do objeto, num verdadeiro sistema de mediações. Reiteramos, conhecer o objeto é alcançar suas múltiplas determinações e relações numerosas.

A construção desse tipo de conhecimento, por sua vez, demanda que se leve em conta o legado já alcançado pela via do próprio método materialista histórico-dialético sobre a captação abstrata, teórica, da realidade concreta. Desse legado destacamos, primeiramente, o fato de que este método supera as dicotomias quantitativo $x$ qualitativo, subjetividade $x$ objetividade, individual $x$ social, indução $x$ dedução e outras, por entender que nelas subjaz um questionamento acerca da possibilidade de construção do conhecimento racional e objetivo da realidade humana em sua complexidade e totalidade.

Os enfoques dicotomizantes, embora possam alçar aparentemente a superação da lógica positivista, acabam por reproduzi-la, à medida que atendem um de seus princípios básicos, qual seja, o princípio da exclusão. Segundo Kopnin (1978), este princípio aponta que dentro de um mesmo sistema dedutivo não coexistem opostos sendo ambos verdadeiros (ou falsos) e assim, um dos polos da oposição acaba por ser excluído.

Diferentemente, a lógica dialética, própria ao método colocado em tela, não é excludente, uma vez que incorpora a lógica formal indo além, isto é, incorpora por superação. Disso resulta a necessidade de uma clara compreensão sobre o que seja oposição e contradição. Levar em conta tais preceitos não significa reconhecer opostos confrontados exteriormente, mas tê-los como interiores um ao outro, no que reside um dos mais importantes preceitos da lógica dialética, denominado identidade dos contrários.

Em conformidade com este princípio, a realidade encerra uma unidade indissolúvel entre opostos, o que determina saber o objetivo como subjetivo, o externo como interno, o individual como social, o qualitativo como quantitativo e vice-versa. Nisso radica a contraposição marxiana aos dualismos dicotômicos asseverados nos princípios de identidade e exclusão próprios à lógica formal.

Outra questão digna de nota refere-se ao fato de que para o materialismo histórico-dialético, conforme anteriormente indicado, o mundo empírico representa apenas a manifestação fenomênica da realidade em suas definibilidades exteriores. Nessa direção, Kosik (1976) afirma que a essência do fenômeno não está posta explicitamente em sua pseudoconcreticidade, não se revelando em sua forma imediata, mas, sim, pelo desvelamento de seu conteúdo. A cons- 
trução do conhecimento científico representa, pois, um percurso de descortinar o pseudoconcreto em direção ao concreto, o que significa dizer, um processo de superação do pseudoconhecimento em direção ao conhecimento fidedigno acerca do real, apreendido em seu movimento e desvelado em suas contradições.

Esse percurso demanda então a apreensão do conteúdo do fenômeno, prenhe de mediações históricas concretas que só podem ser reconhecidas à luz das abstrações do pensamento, isto é, do pensamento teórico. Não se trata de descartar a forma pela qual o dado se manifesta, pelo contrário, trata-se de sabê-la como dimensão parcial, superficial e periférica do mesmo. Sendo assim, o conhecimento calcado na superação da aparência em direção à essência requer a descoberta das tensões imanentes na intervinculação e interdependência entre forma e conteúdo.

Para todos os efeitos, a tradição marxista compreende o conteúdo como expressão unitária do conjunto de propriedades que qualifica um determinado objeto ou fenômeno, bem como determina o grau de grandeza dessa qualidade. Assim, há no conteúdo uma correlação imanente entre qualidade e quantidade. A forma, por sua vez, é a formação relativamente estável de ligações e relações dos elementos que constituem o conteúdo (CHEPTULIN, 1982).

Forma e conteúdo possuem uma correlação orgânica entre si, dependendo um do outro, uma vez que não há conteúdo disforme e, de igual maneira, não existe forma desprovida de conteúdo².

Portanto, se queremos descobrir a essência oculta de um dado objeto, isto é, superar sua apreensão como real empírico, pseudoconcreto, não nos bastam descrições acuradas, sejam elas escritas, filmadas ou fotografadas; não nos bastam relações íntimas com o contexto da investigação, ou seja, não nos basta fazer a fenomenologia da realidade naturalizada e particularizada nas significações individuais que lhes são atribuídas. É preciso caminhar das representações primárias e das significações consensuais em sua imediatez sensível em direção à descoberta das múltiplas determinações ontológicas do real. Todavia, a atividade teórica por si mesma em nada altera a existência concreta do fenômeno. A alte-

2 Cheptulin (1982, p. 268) foi capaz de descrever a lei da correlação do conteúdo e da forma de maneira esclarecedora: "Inicialmente, as mudanças que se produzem no conteúdo não influem no sistema relativamente estável das ligações da forma; elas instalam-se completamente em seu quadro [...]. Mas há um ponto em que as mudanças no conteúdo atingem um nível em que os quadros desse sistema de correlação tornam-se muito estreitos. O sistema relativamente estável começa a entravar o desenvolvimento do conteúdo, a reprimi-lo. Nesse estágio de desenvolvimento do conteúdo, a forma deixa de corresponder ao conteúdo [...]. A não-correspondência da forma com o novo conteúdo, à medida que esse se desenvolve, torna-se sempre mais aguda e finalmente um conflito explode entre o conteúdo e a forma: o novo conteúdo rejeita a antiga forma, destrói o sistema relativamente estável de movimento e, baseado em um novo sistema relativamente estável de movimento (isto é, da forma), transforma-se, passando a outro nível qualitativo. 
ração apenas se revela possível quando a atividade teórica orienta a intervenção prática transformadora da realidade, sendo sua função precípua.

Ademais, o postulado da intervinculação e interdependência entre forma e conteúdo demanda explicitar o significado atribuído ao que seja conteúdo, isto é, apreendê-lo como expressão do processo ontológico da realidade humana e das forças internas que condicionam as formas pelas quais esse processo tem se desenvolvido historicamente. Sendo assim, a captação do conteúdo do fenômeno demanda, do ponto de vista epistemológico, captá-lo num processo dinâmico, expresso na relação dialética entre singular-particular-universal.

Segundo Lukács (1968), nos nexos existentes entre singular-particularuniversal reside o fundamento que sustenta uma autêntica e verdadeira aproximação e compreensão da realidade. Em sua expressão singular, o fenômeno revela o que ele é em sua imediaticidade, sendo indiscutivelmente o ponto de partida da construção do conhecimento; em sua expressão universal revela sua complexidade, suas conexões internas, as leis de seu movimento e evolução, enfim, a sua totalidade histórico-social.

Ocorre, porém, que nenhum fenômeno se expressa apenas em sua singularidade ou universalidade. Como opostos, identificam-se, e a contínua tensão entre eles (singular-universal) se manifesta na configuração particular do fenômeno. Em sua particularidade, o fenômeno assume as especificidades pelas quais a singularidade se constitui em dada realidade de modo determinado, porém, não completo, não universal. Ainda, segundo Lukács (1968), o particular representa para Marx a expressão lógica da categoria de mediação entre o específico (singular) e o geral (universal), impossíveis de serem compreendidos de modo isolado e por si mesmos.

Oliveira (2005, p. 46) chama-nos atenção para a importância de se caracterizar a relação singular-particular-universal no âmbito da investigação científica, afirmando-a como requisito para a compreensão do objeto em suas múltiplas relações e, acima de tudo, para a superação das falsas dicotomias, muito presentes nas ciências humanas. Se preterida a função mediadora da particularidade, as relações acabam sendo consideradas na centralidade de polos aparentemente dicotômicos, perdendo-se de vista as formas pelas quais ocorre a "concretização da universalidade no vir-a-ser da singularidade, mediada pela particularidade". Contudo, a ênfase na relação entre singularidade, particularidade e universalidade não pressupõe a impossibilidade de se ter a particularidade como referência primária na construção do conhecimento, mas, reafirma que é apenas pela análise dialética da relação entre o singular e o universal que se torna possível a construção do conhecimento concreto sobre ela. Entende-se que, por esta via, evita-se que a centralidade conferida à particularidade se converta no 
abandono da construção de um saber na perspectiva da totalidade, assim como tem sido feito pelas pesquisas qualitativas com base no método fenomenológico.

Destaque-se, ainda, que a dialética entre singularidade, particularidade e universalidade encontra amparo no historicismo concreto presente nas obras de Marx e Engels, para quem a produção material da vida engendra todas as formas de relações humanas. A categoria ontológica do trabalho, por conseguinte, torna-se imprescindível em qualquer estudo que se anuncie na perspectiva da totalidade histórica.

Marx, em sua época, levantou de forma contundente o problema da existência humana e, sobretudo, o problema da relação entre indivíduo e gênero humano, entre a singularidade, a particularidade e a universalidade dessa relação, superando tanto a filosofia do idealismo de Hegel como o materialismo intuitivo de Feuerbach. Centrou atenção no materialismo que considera a atividade humana objetiva - o trabalho - como elemento central de análise para os fenômenos humanos, propondo, assim, o materialismo da práxis sintetizado nas célebres Teses sobre Feuerbach (MARX; ENGELS, 2007). O materialismo por ele apresentado - conjuntamente com Engels - colocou em destaque o trabalho social dos homens e as propriedades que adquire historicamente, de sorte que o materialismo dialético se apresenta, em seu pensamento, como possibilidade para a compreensão da realidade que dele resulta, isto é, decorrente do metabolismo homem-natureza produzido pela atividade humana em sua complexidade e movimento.

O processo de produção da vida por meio do trabalho, por sua vez, existe como objetivação dos homens (MARX, 2008), enquanto manifestação de suas próprias forças, expressando-se como natureza humana objetivada e manifestação de suas capacidades essenciais. Ocorre, porém, que a organização social capitalista calcada na propriedade privada dos meios de produção tem obstruído esse processo, uma vez que a atividade do indivíduo e seu resultado, tornando-se independentes, alienados, acarretam a subordinação do produtor ao produto de seu trabalho.

Sob tais condições de alienação, as capacidades dos homens e as possibilidades para seu pleno desenvolvimento se reprimem e se deformam à medida que obliteram a efetiva utilização de todas as forças humanas e humanizadoras. Assim sendo, a exigência para a superação desse fenômeno se identifica com a transformação das condições e das instituições que alienam o trabalho e o trabalhador. Esse é o mais profundo significado do alcance do método materialista histórico-dialético a serviço da construção do conhecimento acerca do real.

Em suma, a adoção do método marxiano pressupõe, como ponto de partida e por meio da lógica indutiva, a apreensão do real imediato; isto é, da representação inicial do todo que, convertido em objeto de análise por meio 
dos processos de abstração, resulta numa apreensão de tipo superior, a caminho do concreto pensado. Destarte, essa ainda não é a etapa final do processo, uma vez que as categorias interpretativas, as estruturas analíticas apreendidas serão contrapostas, dedutivamente, ao objeto inicial, agora captado não mais em sua imediatez sensível, mas em sua totalidade concreta.

Portanto, o referido método tem a prática social como referência fundante da construção do conhecimento, nela residindo os seus critérios de validação. Não apela a negação da lógica formal, mas a torna parte integrante da lógica dialética. Não privilegia processos de dedução em detrimento dos processos de indução ou vice-versa, caracterizada pelo princípio da unidade e luta dos contrários. Igualmente não proclama a lógica subjetivista como critério gnosiológico.

Por conseguinte, podemos sintetizar os fundamentos do método materialista histórico-dialético nos seguintes preceitos: a) superação de enfoques dicotômicos; b) desvelamento do objeto de estudo em sua totalidade, movimento e contradições internas; c) descoberta das tensões consubstanciadas na intervinculação e interdependência entre forma e conteúdo; d) apreensão do objeto nos nexos existentes entre singularidade, particularidade e universalidade, ou seja, em sua historicidade e; e) captação dos traços essenciais do fenômeno em análise, a serem extraídos indutiva e dedutivamente a partir de sua aparência fenomênica.

Isto posto, encaminhamo-nos para a dissertação acerca dos tipos de pesquisa nos quais tais preceitos se objetivam.

\section{Pesquisas empíricas e conceituais à luz do método materialista histórico-dialético}

Salvaguardadas as diferenças tipológicas de pesquisas empíricas e conceituais, sobretudo no que se refere ao caráter procedimental de cada uma delas, o que se pretende abordar aqui é o problema da correlação entre a estrutura teórico-metodológica da investigação científica e o método materialista histórico-dialético, considerando o conjunto de seus fundamentos e seu núcleo categorial.

Nesse sentido, a primeira correlação a ser considerada é aquela que diz respeito à concepção de problema da investigação científica. Com efeito, um problema de pesquisa não se reduz à elaboração imediata de uma pergunta qualquer. A problematicidade de um problema de investigação científica não se sustenta na formulação de uma pergunta ou de uma questão sobre um dado fenomênico qualquer. Sendo expressão de necessidades concretas que impulsionam o pensamento humano em direção a novos conhecimentos, o problema 
de pesquisa não deriva da mera atividade sensorial e experiencial dos homens sobre e na relação com objetos e fenômenos da realidade.

Um problema científico é elaborado no confronto teórico entre o conhecimento já alcançado pela humanidade a respeito dos processos naturais e sociais e aquilo que ainda se faz necessário conhecer. Portanto, há que se destacar aqui que o problema de pesquisa é fundamentalmente a expressão teórica que sintetiza elementos de conhecimentos teóricos alcançados em pesquisas científicas já realizadas e necessidades humanas permanentemente existentes na prática social concreta (PINTO, 1979; SAVIANI, 1991).

Assim compreendido, assegura-se que o problema científico tenha sua formulação alicerçada não no interesse ou vontade estritamente pessoal do sujeito investigador, mas, sobretudo, na dimensão e caráter social que toda investigação deve possuir enquanto processo que parte do real já refletido num dado sistema teórico estruturado visando desenvolvê-lo, avançá-lo ou superá-lo, acrescendo benefícios para a humanidade em geral.

Com base na postulação acerca do problema de pesquisa, decorre a segunda correlação a se destacar: a que diz respeito à formulação da justificativa da pesquisa científica. Coerentemente à concepção de problema de pesquisa, as justificativas de realização dessa atividade humana se firmam na correlação existente entre, minimamente, três pressupostos gerais articulados entre si: primeiro, a necessidade da investigação sobre algo que ainda não existe pesquisa a respeito; segundo, a necessidade de investigação em prol do avanço e desenvolvimento do conhecimento já existente, todavia ainda caracterizado como insuficiente; ou, terceiro, a necessidade de se fazer avançar e desenvolver o conhecimento sobre aquilo que se configura como inadequado ou equivocado, carecendo de revisão num movimento de superação por incorporação.

Como se nota, tais concepções de problema e de justificativa somente serão possíveis de alcançarem formulações numa pesquisa científica à luz do método de investigação aqui abordado se o sujeito pesquisador já for portador de instrumentos analíticos - da alçada do pensamento - que lhe possibilitem estabelecer uma atitude crítica em relação ao objeto ou fenômeno investigado. Isso também carrega determinações para a terceira correlação a ser aqui considerada entre a estrutura teórico-metodológica da pesquisa e o método em questão, qual seja, a formulação das hipóteses de pesquisa.

A hipótese de pesquisa sintetiza, de maneira geral, o processo do conhecimento que já se tem sobre o objeto que se pretende conhecer, ou seja, é a expressão teórica das possibilidades de desenvolvimento do objeto em seu vir-a-ser lógico-histórico. Portanto, cabe ao investigador ter certo nível de conhecimento a respeito das tendências de desenvolvimento do objeto que se alicerçam naquilo que é sua estrutura e dinâmica de funcionamento atual e na- 
quilo em que veio a ser sua gênese e seu desenvolvimento anterior, ou seja, há que se ter conhecimentos já consolidados sobre a problemática de investigação.

Por fim, a quarta correlação a ser ressaltada é a necessária distinção - mas que exige ao mesmo tempo a apreensão de suas interrelações - entre método $e$ procedimentos de pesquisa. Com base naquilo que Marx (2011) sintetizou sobre seus estudos, entende-se método como o confronto e a relação que permite ao sujeito investigador desnudar as formas fenomênicas de um objeto, apreender o seu movimento, encontrar as determinações constitutivas da dinâmica e desenvolvimento do mesmo. Portanto, o método é portador de uma lógica e se sustenta em uma dimensão ontológica e epistêmica, esta última pertencendo à ordem do pensamento.

Com efeito, para se colocar o método em movimento, há que se utilizar de um conjunto de procedimentos investigativos, tais como tratamento teórico-conceitual, cuidados com instrumentos de coleta de dados, valorização de fontes e dados já sistematizados, análises quantitativas e estatísticas, de conteúdo e de discurso, dentre outras. Não resta dúvidas que o investigador necessita dominar dados e procedimentos para alcançar a finalidade da investigação, em última instância, a de penetrar nas propriedades essenciais do objeto ou fenômeno investigado arrancando-lhe sua lógica essencial de funcionamento e desenvolvimento.

Sob essa perspectiva, o método não se identifica com o conjunto de procedimentos adotados na investigação, mas subjuga a si os usos e o seu alcance. Por conseguinte, ressalte-se que no âmbito metodológico não existem diferenças entre pesquisas empíricas e conceituais. Tais distinções ocorrem, apenas, na esfera procedimental, quando as primeiras elegem o objeto de pesquisa a partir, diretamente, do real sensível; e, as segundas, definem como objetos abstrações do pensamento já sistematizadas em conceitos e teorias que operam como mediadoras na captação deste real. Em suma, as investigações empíricas fundam-se numa relação direta (empírica!) do pesquisador com o objeto investigado pela mediação de abstrações do pensamento (teorias e conceitos). As pesquisas conceituais, por seu turno, voltam-se diretamente para as abstrações do pensamento já sistematizadas a respeito de dado objeto ou fenômeno; por conseguinte, o pesquisador estabelece uma relação indireta com o objeto sensível, ora representado conceitualmente. Ambas as formas de pesquisa se ancoram, portanto, na prática histórico-social humana.

No que tange aos procedimentos de pesquisa, entendemos haver uma lacuna no tocante às pesquisas conceituais que culminam, muitas vezes, representadas como meros resumos de publicações sobre o tema. Como possível contributo para a superação desse obstáculo à efetiva construção do conhecimento pela via de tais pesquisas, buscar-se-á apresentar uma breve síntese acerca de seus possíveis procedimentos. 
As pesquisas conceituais, de natureza bibliográfica, demandam, de partida, a eleição do acervo a ser analisado, consubstanciado, então, como campo ou material de análise, não se furtando à delimitação do problema, justificativa e hipótese, conforme explanado anteriormente. Uma vez delimitado o campo teórico de pesquisa, a análise do mesmo pode orientar-se pelos seguintes procedimentos: a) explicitação dos significados dos conceitos apresentados nas obras eleitas e suas correlações tendo em visa a formulação de uma síntese primária em relação ao material em análise; b) identificação da(s) ideia(s) diretriz(es), isto é, das asserções e das ideias explicativas às mesmas (razões) presentes nos textos, ou seja, desvelamento da(s) relação(ções) asserção/razão fundamental(is) nas obras; c) diferenciação e análise comparativa das ideias diretrizes entre si a fim de determinar a importância relativa de cada uma delas no conjunto das produções do(s) autor(es) em foco e; d) operação de síntese, isto é, integração racional dos dados descobertos no conjunto organizado das produções sobre o tema em investigação e em resposta ao problema anunciado.

Ademais, o método materialista dialético, conforme disposto por Marx (2011), não ignora a relação existente entre sujeito investigador e objeto investigado. Ocorre que, para o método em questão, o sujeito investigador tem um papel essencialmente ativo na pesquisa, pois é ele quem deve manejar um conjunto de abstrações de ordem superior que se configura como instrumento de pesquisa essencial para a análise teórica do objeto em questão. Sem esse recurso intelectivo de nada serve os tão disseminados instrumentos de pesquisa como questionários, entrevistas e softwares de análise de dados, dentre outros.

Por outro lado, se o sujeito possui papel fundamental na análise e síntese operatória da pesquisa, para o materialismo histórico-dialético, é o objeto quem, pode-se assim dizer, "comanda" a pesquisa, o que significa dizer que procedimentos e técnicas de pesquisas não são escolhas individuais feitas pelo investigador segundo critérios pessoais, como tampouco devem ser determinados aprioristicamente. É o próprio objeto quem confere as possibilidades do alcance de suas determinações, visto que elas são imanentes do próprio objeto da investigação, e não do desejo ou capacidade intuitiva do pesquisador.

A análise da correlação entre a estrutura teórico-metodológica da investigação científica e o método materialista histórico-dialético, aqui exposta abordando a dimensão do problema, da justificativa, da hipótese e dos procedimentos da investigação, por sua vez, está relacionada a um problema político-formativo que atinge diretamente - mas não somente - os pesquisadores em educação que reivindicam realizar pesquisas sustentadas no método aqui discutido, a saber, o problema da formação do pesquisador e nesse âmbito o papel do ensino.

Considerando os limites desse artigo para se aprofundar a discussão quanto a esta questão, apenas se afirma o quão prejudicial vem sendo a formação de 
professores em nível de graduação e pós-graduação afetada por um conjunto de teorias pedagógicas e perspectivas formativas que de maneira geral negam, recusam e recriminam o ato de ensinar e a tarefa de transmissão de sólidos conhecimentos das ciências, da filosofia e das artes na formação de professores e futuros investigadores em educação.

Para além daquilo já evidenciado, por exemplo, em Della Fonte (2010), Duarte (2006, 2010), Martins (2010) e Moraes (2001) quanto aos desdobramentos acadêmicos, éticos, políticos e filosóficos advindos da fragilidade da formação na área da educação, ressalta-se aqui uma implicação que cada vez mais ganha notoriedade no que diz respeito ao processo de desenvolvimento de pesquisas nesta área, qual seja, o que se poderia chamar de procedimentalização das pesquisas, caracterizada por demasiada preocupação com a descrição de procedimentos de pesquisa - tomados como "método" - e, como consequência, uma desmetodização dos processos investigativos ${ }^{3}$, reflexo de um culto ao silenciamento e ausência de reflexão crítica quanto ao método da investigação em educação. O resultado desse processo é exatamente o oposto ao que é uma das premissas e exigências da investigação científica pautada no materialismo histórico-dialético: pesquisadores com potenciais capacidades de operar com o pensamento teórico-abstrato de forma crítica em busca da apreensão, compreensão e explicação de objetos de pesquisas e fenômenos investigativos no campo da educação.

\section{Considerações finais}

Ao apresentar esses postulados metodológicos do materialismo histórico-dialético, espera-se contribuir para as atuais investigações em educação, visto terem tido nas últimas décadas um importante avanço no campo das ciências humanas e sociais. Tem existido um conjunto enorme de produção científica na área a qual tem procurado debater - com muita qualidade e competência procedimentos e técnicas de investigação nas pesquisas educacionais.

Não obstante, há que se ter a preocupação de que as técnicas e os procedimentos de análise nas pesquisas compõem um - não menos importante passo ou momento da investigação científica, sendo que essa necessariamente pressupõe um método que é expressão da relação sujeito-objeto que permite ao sujeito investigador desnudar as formas fenomênicas de um objeto investigado,

3 Lavoura e Martins (2017) buscaram realizar uma análise semelhante, não obstante, circunscrita aos processos de ensino e aprendizagem na educação escolar, desenvolvendo-se aquilo que denominamos de "didatização e desmetodização" do ensino. 
apreendendo o seu movimento, encontrando as determinações constitutivas da dinâmica, da estrutura, da gênese e do desenvolvimento desse objeto.

Para o materialismo histórico-dialético, o processo referente à indagação de como é possível conhecer um objeto (dimensão epistemológica) está internamente contida num processo de maior expressão e objetividade, qual seja, a indagação de que as coisas, os objetos e os fenômenos da realidade verdadeiramente são (dimensão ontológica).

Como exposto anteriormente, esse caminho metodológico investigativo possui como ponto de partida o dado imediato do objeto investigado, aquilo que é a aparência, um sinalizador, um indicador de processos que não se mostram em sua plenitude. A factualidade imediata do objeto é a expressão coagulada de processos sem nexos.

Cabe ao sujeito investigador, utilizando-se da abstração, mediante a capacidade da análise, ir além da factualidade do dado imediato para alcançar a identificação dos processos que ela - factualidade - é aparência. Ir além da factualidade é deslocar-se da empiria à concretude real do objeto ou fenômeno, descobrindo seus traços essenciais que se revelam por meio das categorias analíticas que são expressões das determinações do objeto. Sem a capacidade de abstrair-se do fato dado é impossível o conhecimento teórico. Como afirma Netto (2011), os fatos nada dizem, são inaudíveis na sua forma imediata. O conhecimento teórico dissolve a imediatez factual aparentemente à mostra no processo de investigação, de modo que o objeto investigado não é um dado, mas expressão de um processo.

Em termos de fundamentos e pressupostos metodológicos, acredita-se que os elementos aqui apresentados se constituem em grande desafio às investigações em educação.

\section{REFERÊNCIAS}

CHEPTUlin, A. A dialética materialista: categorias e leis da dialética. São Paulo: Alfa-Omega, 1982.

DELLA FONTE, S. S. Agenda pós-moderna e neopositivismo: antípodas solidários. Revista Educação e Sociedade, Campinas, v. 31, n. 110, p. 35-56, jan./mar. 2010.

DUARTE, N. O debate contemporâneo das teorias pedagógicas. In: MARTINS, L. M.; DUARTE, N. (Orgs.). Formação de professores: limites contemporâneos e alternativas necessárias. São Paulo: Cultura Acadêmica, 2010. p. 33-50. 
DUARTE, N. A pesquisa e a formação de intelectuais críticos na pós-graduação em educação. Revista Perspectiva, Florianópolis, v. 24, n. 1, p. 89-110, jan./jun. 2006.

KOPNIN, P. V. A dialética como lógica e teoria do conhecimento. Rio de Janeiro: Civilização Brasileira, 1978.

KOSIK, K. Dialética do concreto. Rio de Janeiro: Paz e Terra, 1976.

LAVOURA, T. N.; MARTINS, L. M. A dialética do ensino e da aprendizagem na atividade pedagógica histórico-crítica. Revista Interface: comunicação, saúde e educação, 21(62), p. 5-18, 2017.

LUKÁCS, G. Marxismo e teoria da literatura. Rio de Janeiro: Civilização Brasileira, 1968.

LUKÁCS, G. Para uma ontologia do ser social II. São Paulo: Boitempo, 2013.

LUKÁCS, G. Existencialismo ou marxismo. São Paulo: Senzala LTDA, 1967.

MARTINS, L. M. O legado do século XX para a formação de professores. In: MARTINS, L. M.; DUARTE, N (Orgs.). Formação de professores: limites contemporâneos e alternativas necessárias. São Paulo: Cultura Acadêmica, 2010. p.13-32.

MARX, K. O capital: crítica da economia política - o processo de produção do capital. Rio de Janeiro: Civilização Brasileira, 2008.

MARX, K. Grundrisse: manuscritos econômicos de 1857-1858: esboço da crítica da economia política. São Paulo: Boitempo, 2011.

MARX, K.; ENGELS, F. A ideologia alemã. São Paulo: Boitempo, 2007.

MORAES. M. C. M. Recuo da teoria: dilemas na pesquisa em educação. Revista Portuguesa de Educação, 14(1), p. 07-25, 2001.

NETTO, J. P. Introdução ao estudo do método de Marx. São Paulo: Expressão Popular, 2011.

OLIVEIRA, B. A. A dialética do singular-particular-universal. In: ABRANTES, A. A.; SILVA, N. R.; MARTINS, S. T. F. (Orgs.). Método histórico-social na Psicologia Social. São Paulo: Vozes, 2005.

PINTO, A. V. Ciência e existência: problemas filosóficos da pesquisa científica. Rio de Janeiro: Paz e Terra, 1979.

SAVIANI, D. Educação: do senso comum à consciência filosófica. 10. ed. São Paulo: Cortez/Autores Associados, 1991.

Texto recebido em 14 de maio de 2018. Texto aprovado em 07 de junho de 2018. 